\title{
EXHIBITORS AS OF 2/1/00
}

Exhibits and posters are located in Oasis 3, Palm Springs Convention Center.

Please check the on-site handout for changes and additions to this list.

\author{
Applied Imaging Corporation \\ 2380 Walsh Ave., Bldg. B \\ Santa Clara, CA 95051 \\ 408-562-0250 / Fax 408-562-0264 \\ Email: lnunez@aicorp.com \\ www.aicorp.com \\ Applied Imaging manufactures and markets \\ state-of-the-art cytogenetic workstations. The \\ product line includes the CytoVision, \\ ChromoFluor, and ChromoScan systems. These \\ systems perform automated karyotyping, FISH, \\ $\mathrm{CCH}, \mathrm{MFISH}, \mathrm{RxFISH}$ and fully integrated slide \\ scanning. Headquartered in Santa Clara, \\ California, with offices in Newcastle upon Tyne, \\ U.K.
}

Athena Diagnostics, Inc.

Booth 10

377 Plantation St.

Worchester, MA 01605

508-756-2886/ Fax 508-753-5801

Email: dlafountaine@athenadiagnostics.com www.athenadiagnostics.com

Athena Diagnostics, Inc., is the only clinical reference laboratory solely dedicated to serving the medical community's need for diagnostic testing targeted to neurologic disorders, including Alzheimer disease, MS, peripheral neuropathy and neurogenetics.

\section{Baylor College of Medicine}

Booth 18

Medical Genetics Laboratories

6550 Fannin, Suite 920

Houston, TX 77030

713-798-3253 / Fax 713-798-4187

Email: sbinder@bcm.tmc.edu

www.bcm.tmc.edu/medgen/

The Baylor Medical Genetics Laboratories offer a broad range of diagnostic genetic tests including biochemical genetics, cytogenetics, FISH analysis, and DNA diagnostics. The laboratories are affiliated with Baylor's Department of Molecular and Human Genetics-a leader in the field of Medical Genetics. We have recently launched several new diagnostic tests. Stop by our exhibit for a current list.
Cytocell Ltd./Rainbow Scientific, Inc. Booth 6 83 Maple Ave. Windsor, CT 06095

860-298-8382 / Fax 860-298-8586

Email: cytocell@msn.com

www.cytocell.co.uk

Cytocell 2000 broadens its range of fluorescent in situ hybridization (FISH) probes with Aquarius $^{T M}$ liquid probes for microdeletion syndrome analysis including: DiGeorge/VCFS, Prader-Willi/Angelman, Smith-Magenis, MillerDieker, Williams, Wolf-Hirschorn and cri-duchat. Chromoprobe Choices ${ }^{\mathrm{TM}}$ is the new purchasing format that provides for true singletest purchasing of any FISH probe from Cytocell's extensive probe menu of enumeration, whole chromosome painting, microdeletion, telomere-specific, and hematology probes.

Eastern Medical Publishers

Booth 1

3600 Commerce Dr., Suite 613

Baltimore, MD 21227

410-536-9300 / Fax 410-536-9305

Email: empltd@aol.com

Eastern Medical Publishers offers the latest, upto-date clinical reference publications, books, journals and CD-ROM. Please visit our booth for convenient, one-stop review of current publications from a broad range of publishers including Marcel Dekker, Oxford University Press, Parthenon Press, Humana Press, McGraw'Hill, Thieme and others.

\section{Genetic Alliance}

Booth 4

4301 Connecticut Ave., NW, Suite 404

Washington, DC 20008-3204

202-966-5557 or 1-800-336-GENE helpline

Fax 202-966-8553

Email: info@geneticalliance.org

www.geneticalliance.org

The Genetic Alliance (formerly Alliance of Genetic Support Groups) is an international coalition of consumers. professionals and support group organizations working together to enhance the lives of everyone impacted by 
genetics. Activities include: Information Resource Center, accessible by Helpline (1-800336-GENE) or www.geneticalliance.org; provider education targeting healthcare professionals, primary care providers, medical students and managed care; technical assistance to support groups; and public policy involvement.

\section{Genetic Disease Branch}

Booth 11

California Dept. of Health Services

2151 Berkeley Way, Annex 4

Berkeley, CA 94704

510-540-3036 / Fax 510-540-2196

Email: lfeuchtb@dhs.ca.gov

This exhibit highlights the Genetic Disease Branch (GDB), which provides high quality, accessible and affordable prenatal and newborn screening throughout California to screen for birth defects and heritable disorders. The GDB programs promote optimal pregnancy outcomes through genetic information and education, with an emphasis on public-private partnerships.

\section{Genetic Health}

1720 S. Amphlett Blvd., Suite 130

San Mateo, CA 94402

650-655-7255 / Fax 650-655-7299

Email: lherrle@genetichealth.com

www.genetichealth.com

Genetic Health is developing Internet-based genetic educational resources and services for individuals, families and healthcare providers. GeneticHeatlh.com will enable visitors to learn about genetics and inherited risk for common, adult-onset diseases, assess their own risk, find genetics professionals, and stay current on developments in genetics and disease prevention.

\section{Genzyme Genetics Corporation Booth 13} 15 Pleasant St.

Framingham, MA 01701-9322

508-270-2204 / Fax 508-872-5663

Email: lcoady@genzyme.com

www.genzyme.com

Genzyme Genetics provides a comprehensive range of genetic diagnostic services and clinical programs supported by a national network of laboratories and genetics professionals. Materials summarizing test menu and protocol for prenatal, cancer and DNA diagnostic programs will be available. Information highlighting newly developed clinical programs will be on display.

\section{Greenwood Genetic Center}

One Gregor Mendel Circle

Greenwood, SC 29646

864-941-8100 / Fax 864-941-8114

Email: jpelkey@ggc.org

www.ggc.org

Since 1974, the Greenwood Genetic Center has been a not-for-profit clinical, diagnostic, research and educational institute. The Center provides comprehensive genetic counseling services and diagnostic studies including chromosome analysis, metabolic testing, molecular DNA analysis, prenatal screening and fetal pathology. Professional education publications include Counseling Aids for Geneticists and Growth References.

Hamilton Thorne Research

100 Cummings Center, Suite 102C

Booth 20

Beverly, MA 01915

978-921-2050 / Fax 978-921-0250

Email: smccain@hamiltonthorne.com www.hamiltonthorne.com

John Wiley \& Sons, Inc. 605 Third Ave.

New York, NY 10158

212-850-6046 / Fax 212-850-6617

Email: dimus@wiley.com

www.wiley.com

Founded in 1807, John Wiley \& Sons, Inc. is an independent, global publisher of print and electronic products. Wiley specializes in scientific and technical books, journals, textbooks and education materials for colleges and universities, and professional and consumer books and subscription services. Please visit our web site.

\section{LabCorp}

Booth 7

500 South Main, Suite 301

Burlington, NC 27215

1-800-222-7566/Fax 336-513-4121

Email: tatumr@labcorp.com

www.labcorp.com

LabCorp is a national clinical reference laboratory dedicated to the highest standards of quality, service, and professionalism. Educational literature describing services and 
capabilities will be available.

\author{
Lippincott, Williams \& Wilkins \\ $227 \mathrm{E}$. Washington Square \\ Philadelphia, PA 19106-3780 \\ 215-238-4200 / Fax 215-238-4404
}

\section{March of Dimes}

Birth Defects Foundation

1275 Mamaroneck Ave.

White Plains, NY 10605

914-997-4749 or 888-MODIMES

Fax 914-997-4763

Email: brobertson@modimes.org

www.modimes.org

The March of Dimes is a national voluntary health agency whose mission is to improve the health of babies by preventing birth defects and infant mortality. Founded in 1938, the March of Dimes funds programs of research, community services, education and advocacy to save babies. Ask us about pre-pregnancy, pregnancy, birth defects, genetics, drug use and environmental hazards during pregnancy and related topics.

\section{National Institute on Alcohol Abuse and} Alcoholism (NIAAA)

Booth 17

c/o CSR, Incorporated

1400 Eye St., NW, Suite 200

Washington, DC 20005

202-842-7600 / Fax 202-842-0418

Email: arcadconference@csrincorpo.com www.csrincorporated.com

The National Institute on Alcohol Abuse and Alcoholism, National Institutes of Health, is the primary organization funding research into the causes, consequences, and treatment of alcohol abuse and alcoholism in the U.S. NIAAA's exhibit will feature research grant information, research publications, and tools to assist researchers, such as the ETOH database, the world's largest online bibliographic database on alcohol research.

Olympus America, Inc.

Booth 16

Two Corporate Center Dr.

Melville, NY 11747

1-800-446-5967 / Fax 631-844-5112

Email:micro@olympus.com

www.olympus.com

Olympus features the modular, Provis AX70

advanced Research Microscope, with U.I.S. optics, for use in all modes of microscopy. The ergonomically designed stand provides extraordinary stability for excellent photo and video documentation. Also displayed, the BX60 high end fluorescence research microscope, along with digital imaging and image capture systems.

\section{Osteogenesis Imperfecta \\ Foundation}

Booth 21

804 West Diamond Ave., Suite 210

Gaithersburg, MD 20878

301-947-0083 / Fax 301-947-0456

Email: hshapiro@oif.org

www.oif.org

Visit the Osteogenesis Imperfecta Foundation exhibit for resources and information for parents, educators and counselors. Clinical care guidelines and diagnostic test information will help you advise and support families and teach students. Video and print resources are available to help new parents cope. Research grants available for new investigators.

Perceptive Scientific

Booths 27\&28

Instruments, Inc.

2525 South Shore Blvd., Suite 100

League City, TX 77573

281-334-3027 or $1-800-288-3027$

Fax 281-538-2222

Email: info@persci.com

www.persci.com

Perceptive Scientific Instruments, Inc. (PSI) is a digital imaging company that provides practical, easy to use imaging solutions for the

Cytogenetics laboratory. PSI's products include software/hardware for classical brightfield

karyotyping, fluorescence in situ hybridization

(FISH), comparative genomic Hybridization

(CGH), 24 Color Karyotyping

and Fiber FISH.

Progeny Software, LLC

Booth 5

1025 Widener Lane

South Bend, IN 46614

219-299-4900 or 1-800-PROGENY

Fax 219-299-1601

Email: cbathon@progeny2000.com

www.progeny2000.com

Progeny Software is a suite of pedigree

management tools for analyzing and displaying

family history. Utilizing a powerful database, 
data is displayed in pedigree, data entry, and spreadsheet formats. Generate reports, query populations, import/export data, display traits/haplotypes. Cut/paste pedigrees into grant applications/publications. Collect patient data electronically by phone or website.

\section{University of Miami School of}

\section{Medicine}

Booth 8

1550 NW 10th Ave.

PAP Bldg., Room 410 (R-5)

Miami, FL 33136

(305) 243-6586

Fax (305) 243-6970

neuropat@med.miami.edu 